\title{
GLOBALIZACIÓN Y EDUCACIÓN DESDE UNA PERSPECTIVA DE GÉNERO
}

\section{Remedios Martínez Verdú \\ Universidad de Alicante}

\section{Introducción}

Uno de los movimientos de mayor relevancia en el mundo ha sido el feminismo. Asimismo, la globalización es una fuerza multidimensional que también ha cambiado nuestra sociedad contemporánea. Este artículo intenta unir estos dos movimientos dispares y traer un tercero a discusión, el tema de la educación pública.

La globalización es un fenómeno distinto de la internacionalización y la multinacionalización. Es una etapa más de un proceso de evolución del sistema económico, pero tiene características distintivas muy marcadas. El Informe de Desarrollo Humano de la Organización de las Naciones Unidas Para el Desarrollo plantea que la salud pública ha disminuido, lo cual puede corroborarse en la propagación del SIDA, hay una degradación ambiental creciente, un subempleo o desempleo, mientras que la relevancia de la educación, y el tipo de educación que se demanda ha cambiado drásticamente, está sufriendo cambios constantes bajo los efectos de la globalización., su estructura se está alterando para facilitar su competitividad en un mercado abierto y global. La educación de las mujeres y la disparidad de género en los países en vías de desarrollo constituyen un gran problema.

Cuestiones de género, 2006, $\mathrm{n}^{\circ} 1$, pp. 53/72 


\section{Globalización y economía}

En sentido estricto la globalización es el proceso resultante de la capacidad de ciertas actividades de funcionar como una unidad, en tiempo real, a escala planetaria (Castells, 1999). Así, las decisiones y actividades en cualquier lugar tienen repercusiones significativas en sitios muy distantes, simultáneamente. El proceso ha sido apoyado por la revolución informática y de las comunicaciones que da la base tecnológica para que esa operación en tiempo real pueda producirse. La globalización es el hecho social más significativo de las tres últimas décadas del siglo XX y desde luego, de comienzos del siglo XXI, y está determinando un profundo proceso de transformación social que se está produciendo después de la revolución industrial. En estas nuevas sociedades que se están gestando desde hace ya tres décadas, se pueden identificar nuevas formas de estratificación social y nuevas relaciones.

La disolución de la antigua Unión Soviética y el desmantelamiento de la China Comunista han llevado a la conclusión, prematura por cierto, de que el socialismo fue un fracaso y que el libre mercado es superior. De ese modo, la globalización ha reemplazado a la Guerra Fría como el esquema explicativo dominante (Friedman, 1999). Este fenómeno ha traído nuevos actores a la política, a veces inclusive con más autoridad sobre los estados nacionales como la Organización Mundial de Comercio, que aporta nuevas reglas mediante acuerdos multilaterales en comercio, servicios y en la propiedad intelectual (UNDP, 1999), y el Fondo Monetario Internacional, que domina la gestión financiera de muchos países a través de los programas de austeridad fiscal. Los nuevos actores incluyen las corporaciones transnacionales y las redes mundiales de ONGs y otros grupos que transcienden las fronteras nacionales.

Las políticas neoliberales de los gobiernos estadounidense y británico y su expansión global gracias al colapso de la Unión Soviética son la causa y el origen del llamado proceso de globalización, dado que no es ni más ni menos que la internacionalización de las economías estadounidenses y británicas bajo criterios neoliberales dominantes. De ahí que las políticas llevadas a cabo por los gobiernos 
Globalización y educación desde una perspectiva de género

promuevan los intereses económicos y financieros, y como EE.UU. arrastra a muchos países junto con Inglaterra y tiene una importante influencia en organismos internacionales como el FMI, OMC o Banco Mundial y apoyado por el G-7, la globalización se puede definir como el resultado de las decisiones políticas concretas tomadas por los gobiernos de EE.UU.

El proceso de reestructuración global se produce de forma desigual. Se observan disparidades regionales, entre sectores socioeconómicos y de género, con diferentes consecuencias muchas de las cuales implican deterioro de la calidad de vida de las personas.

Sin duda, la globalización ha creado nuevos mercados, mediante una revolución en la comunicación y el transporte, y leyes que aseguran la demolición de barreras al intercambio comercial. Este fenómeno ha traído tanto un aumento en el ingreso como en la desigualdad social entre países. Mientras que a comienzos de los 70 los países en desarrollo constituían un cuarto del comercio, ellos actualmente representan un tercio de este intercambio. Sin embargo, esto indica un crecimiento económico y no un crecimiento en el empleo; por ello, se siguen acrecentando las desigualdades en ingresos y en recursos tales como la tierra, propiedad y el capital humano.

En algunos países ha dado lugar a un rápido crecimiento. En otros ha llevado a la recesión. Otras regiones han quedado al margen de la economía global. La globalización no es una ideología o una moda, sino que representa una tendencia irreversible y los países ya no pueden optar por un desarrollo detrás de las fronteras.

Los principios del llamado Consenso de Washington, que constituyen las bases del ajuste estructural, fueron considerados fines en sí mismos y aplicados como dogma. Partían del supuesto de que si se lograban los objetivos macroeconómicos, el resto funcionaría automáticamente. Se suponía la existencia de políticas cuyo resultado era que todos ganaban en el proceso, que estas aseguraban el crecimiento y que el crecimiento por sí solo llevaba a la disminución de la pobreza. 
El discurso de organismos como el Fondo Monetario Internacional (FMI) y el Banco Mundial, que como es por todos conocido jugaron un papel activo en la reestructuración, así como de la Organización Mundial del Comercio (OMC), muestran un cierto cambio.

Michel Camdessus, en su último discurso como director gerente del Fondo Monetario Internacional, pronunciado en la X Reunión de la Conferencia de las Naciones Unidas sobre Comercio y Desarrollo (UNCTAD), planteó que "no basta con aumentar el tamaño de la torta. La forma en que se distribuye es muy relevante para el dinamismo del desarrollo". "Si los pobres quedan fuera sin esperanzas, la pobreza debilitará el tejido de nuestras sociedades a través de la confrontación, la violencia y el desorden civil”. El Banco Mundial y el FMI señalaron en dicha reunión el aumento de la brecha entre los países pobres y ricos: “el abismo entre las naciones más prósperas y las más desheredadas es moralmente escandaloso, en lo económico representan un malgasto de recursos y son potencialmente explosivos en lo social”. Consideran que la apertura de los países más ricos a las exportaciones de los países pobres, permite incluir a estos últimos en los beneficios del comercio internacional más abierto. Hay un reconocimiento explícito de que los países en desarrollo se han vistos bloqueados por el proteccionismo de los países desarrollados.

La globalización ha beneficiado a los países industrializados y ha permitido la mejoría económica de varios países en Asia, notablemente la China y la India, dos países que contienen nada menos que a tres quintos de la población mundial. Ante esta figura, algunos observadores esgrimen dos argumentos: (1) si los países asiáticos lo hicieron, todos los otros países si se esfuerzan también lo podrían lograr; y (2) la desigualdad no importa, lo que importa es que la torta se va agrandando más.

La riqueza de los países industrializados van en aumento. En 1993, 10 países concentraban el $84 \%$ de la inversión mundial en investigación y desarrollo (UNDP, 1999), actividades mediante las cuales se fomentan las tecnologías y avances científicos que mayor precio obtienen en el mercado. El director de la OMC sugiere que las grandes potencias deben abrir sus mercados a los productos de las naciones más pobres 
Globalización y educación desde una perspectiva de género

si desean el apoyo de éstas para una nueva ronda de negociaciones globales de comercio.

\section{Género y globalización}

La globalización ha traído resultados contradictorios para las mujeres. Por una parte, la difusión de ideas sobre derechos humanos han generado cambios positivos en cuanto a su inclusión en el trabajo remunerado, la educación, la política, y en todos los ámbitos de la sociedad. Esto contribuye a su bienestar y aumento de su sentido de autoestima y autonomía. Por otra parte, la globalización ha significado muchas veces su inserción laboral en puestos de baja remuneración y movilidad, bajo contextos de patriarcados renovados, pero aún patriarcados. La fuerte presencia femenina en la industria de exportación (agrícola y no agrícola) refleja la ubicación de la mujer en trabajos en el umbral de la pobreza.

Los efectos de la globalización neoliberal sobre la vida de las mujeres son tan significativos como para que la feminización de la pobreza o la segregación genérica del mercado laboral se traduzcan en cifras imposibles de obviar, a pesar de que los Informes de Desarrollo Humano de Naciones Unidas ya no segreguen por género sus tasas. En la extensa bibliografía crítica sobre globalización neoliberal se pueden observar análisis minuciosos sobre el nuevo funcionamiento del capitalismo internacional, sobre el aumento de la desigualdad, pero escaseen las investigaciones que visibilizan otra realidad empíricamente contrastable, como es la desigualdad de género y la pobreza de las mujeres. Lo cierto es que la pobreza, la supervivencia, la exclusión y el trabajo gratuito se están feminizando cada vez más.

El imaginario capitalista, que reproduce, infinitamente, el discurso hegemónico patriarcal destaca como elemento predominante las bondades del sistema para complacer necesidades materiales. A los individuos se les construye una única conclusión posible: dentro del sistema todo, fuera de él, nada es válido. Un recurso legitimador de este imaginario ha sido proponer alternativas dentro de los mecanismos 
regulatorios del propio sistema. Las contradicciones y conflictos valorativos se presentan como manifestaciones de disfuncionalidad que se deben a desajustes institucionales o son consecuencias del mal desempeño de ciertos funcionarios públicos. El capitalismo neoliberal está renovando el pacto histórico e interclasista con el patriarcado a partir de unos nuevos términos. Está eliminando una buena parte de las cláusulas, pero está dejando intacta la médula de ese pacto que se traduce en subordinación a los varones y explotación capitalista y patriarcal. Desaparece paulatinamente la figura del varón como proveedor económico de la familia y aparece una nueva figura, la 'proveedora frustrada', tal y como argumentan Heidi Hartman y Celia Amorós. Esta mujer que se inserta en el mercado de trabajo global se ve atrapada en una jornada interminable a causa del aumento del trabajo gratuito e invisible del hogar y ahora, además, accede al mercado de trabajo como trabajadora 'genérica'.

Manuel Castells subraya que "el predecible ascenso del hombre del organigrama ha sido sustituido actualmente por el de la mujer flexible". Las trabajadoras 'genéricas' son el modelo ideal para la nueva economía neoliberal: son flexibles e intercambiables.

Dos sistemas hegemónicos - patriarcado y capitalismo neoliberal- han pactado nuevos y más amplios espacios de trabajo para las mujeres, que se concretan en la renovación de la subordinación a los varones y en nuevos ámbitos de explotación económica y doméstica. No deja de ser sorprendente que uno de los muchos efectos asociados a la globalización sea la informalización del trabajo y que no se subraye el hecho de que la mayoría de ese trabajo mal pagado y sin derechos laborales lo realicen mujeres. La idea de fondo que subrayan las investigaciones feministas sobre globalización es que no pueden entenderse los procesos asociados a la globalización sin la aplicación de la variable de género a estos procesos sociales.

Uno de los efectos más significativos de los programas de ajuste estructural es el crecimiento del trabajo gratuito de las mujeres en el hogar. Este hecho es el resultado directo de los recortes de las ayudas sociales por parte del estado, pues aquellas funciones de las que el estado abdica (salud y nutrición, entre otras) vuelven a recaer 
invariablemente en la familia y nuevamente son asumidos por las mujeres, del mismo modo que antes de que se aplicasen políticas sociales. Sin embargo, hay que subrayar que no sólo el recorte de las políticas sociales tiene efectos negativos para las mujeres, también las políticas macroeconómicas ejercen una influencia significativa sobre el trabajo no remunerado y sobre las condiciones de vida de las mujeres.

En general, hay que señalar que los recortes en el gasto social tienen como efecto el incremento del trabajo gratuito que realizan las mujeres en el marco familiar, mientras que las políticas que aumentan el gasto público reducen el trabajo gratuito de las mujeres, fundamentalmente porque el estado se hace cargo de tareas reproductivas o porque el empresariado asume algunas cargas, como las bajas por maternidad. Las mujeres, al ser uno de los sectores de población más pobres, son quienes más se han beneficiado con los programas sociales y por ello mismo son quienes más acusan las medidas de ajuste estructural, puesto que son estos servicios a los que se aplican los recortes en los presupuestos nacionales. ¿Cuál es el resultado de la aplicación de estas políticas de ajuste estructural sobre las mujeres? Lo primero que hay que subrayar es que influyen asimétricamente sobre las relaciones de género. Y es que el estado redefine y expande lo 'privado' para así invisibilizar los costes de desplazamiento de la economía remunerada a la no remunerada.

Los efectos de las políticas neoliberales son distintos para las mujeres de los países del Norte y de los del Sur, afectan más negativamente a las mujeres de los países en desarrollo que a las de los países del primer mundo. Y este hecho está relacionado con el grado de desarrollo de los derechos sociales, de las democracias y de la formación cultural de cada sociedad.

De otro lado, no puede soslayarse el hecho de que en los países del norte se aplican en mayor o menor medida políticas de acción afirmativa como resultado de la movilización política de las mujeres en organizaciones feministas desde hace décadas. La fragilidad de la democracia y la debilidad de la sociedad civil son caldos de cultivo idóneos para las políticas neoliberales y son, por tanto, más favorables para la explotación de las mujeres. Pese a todo, en los países desarrollados están apareciendo 
ciertas características de subdesarrollo, debido a los recortes en el sistema de seguridad social y a la marginación de grupos cada vez mayores de poblaciones excluidas del acceso al empleo formal.

Manuel Castells señala que la globalización es un proceso que está intensificando cada vez más la segregación del mercado laboral entre dos clases de trabajadores: los autoprogramables y los genéricos. La diferencia clave para diferenciar a ambos es la educación, aunque advierte que no hay que confundir educación con cualificación profesional. Subraya que “quien posee educación, en el entorno organizativo apropiado, puede reprogramarse hacia las tareas en cambio constante del proceso de producción. Por el contrario, el trabajador genérico es asignado a una tarea determinada, sin capacidad de reprogramación, que no presupone la incorporación de información y conocimiento más allá de la capacidad de recibir y ejecutar señales".

Entre los trabajadores autoprogramables la mayoría son varones y entre los genéricos la mayoría son mujeres. El mercado mundial de trabajo muestra una creciente diferenciación entre una capa de trabajadores mayoritariamente varones altamente cualificados con ingresos altos y una 'periferia' creciente excesivamente representada por mujeres e inmigrantes con empleos no permanentes, subcontratados, bajo condiciones laborales precarias y con ingresos bajos e inestables.

Los datos estadísticos reflejan un cambio en la composición de género en el mercado mundial de trabajo. En definitiva, en casi todas las regiones del mundo la participación de las mujeres en el mercado aumentó, pero las condiciones bajo las cuales se insertan las mujeres en ese mercado son desfavorables. La "feminización laboral", tendencia que se manifestó en la economía mundial a partir de la posguerra y alcanzó su auge en los años 60, adquiere ahora nuevos matices: las mujeres constituyen la fuerza principal de trabajo para el creciente sector de los servicios, donde realizan tareas de bajo estatus y poco salario. Según datos del PNUD, el 71\% de las mujeres empleadas formalmente se concentran en cinco grupos ocupacionales, educación, enfermería, oficina, ventas y servicios, la mayoría en los puestos peor remunerados. 
Las apologías de "lo posible y lo necesario" y la justificación de los males existentes es un elemento imprescindible en el discurso neoliberal y en su estrategia cultural. La justificación de la pobreza, de la baja moral pública, de la inseguridad social, de las violaciones de los derechos humanos es el reverso de la crítica al sistema. Con ella se quiebran las nociones sociales y colectivas en el plano simbólico y se instalan, en su lugar, la noción de paradigma hegemónico con sujetos individuales y fragmentados, con esto se pone freno a la creación de conceptos y realidades que promuevan alternativas de liberación.

Está tan universalizada la cultura capitalista y tan asimilados sus sistemas de valores que es común rechazar o no aceptar cuestionamientos a su esencia. Por lo general ocurre que resulta difícil ver lo que está fuera de nuestro campo visual ya sea por asumirlo tal y como es o por impotencia. El orden capitalista, como bien reconocen se ideólogos liberales y neoliberales, dedica especial atención a la fundamentación valorativa de sus referentes y a la conformación de una estructura subjetiva de valores que garanticen la estabilidad de dicho orden.

Dicha estructura oculta el significado real del sistema, la maximización de la ganancia, pero en su lugar ofrece normas conductuales que guían a los individuos y muestran el modo de cómo asegurar la posibilidad de éxito o el fracaso de una acción, el modo adecuado de relacionarse los individuos, el "modo de hacer las cosas" sin establecer diferenciación entre el saber, hacer y desear.

El patriarcado en su versión neoliberal y globalizado acentúa sus significados clásicos: el individualismo, el divorcio entre lo público y lo privado, la desigualdad natural de género. Como valores del orden, no están en discusión. "Se aceptan, si se quiere vivir y por esta razón se excluye a todo aquel que no los acepte o luche contra ellos".

Todos estos motivos muestran la necesidad de que el feminismo construya un discurso crítico hacia la globalización económica. Los datos apuntan a la necesidad de que los argumentos feministas tengan un espacio relevante en los movimientos antiglobalización, hasta el punto de que las alternativas que se formulen al 
neoliberalismo tengan como uno de sus ejes centrales la desigualdad de género. Esto requiere que el feminismo se articule críticamente contra la feminización de la exclusión social y contra la feminización de la supervivencia que se concreta en la industria del sexo y en las actividades económicas criminales, pues si se construyen alternativas creíbles a la globalización neoliberal y el feminismo está ausente de su formulación y de su defensa política, después no podrá obtener ninguno de los beneficios de ese éxito político.

La globalización neoliberal capitalista ha producido cambios tan vertiginosos, y tantas rupturas teóricas y cotidianas que no es de asombrar, como dice Noam Chomski, el estado de desesperación, ansiedad, falta de esperanza, enojo y temor que prevalece en el mundo fuera de los sectores opulentos y privilegiados y del sacerdocio comprado que cantan alabanzas a nuestra magnificencia, una característica notable de nuestra cultura contemporánea.

\section{Internet y el feminismo}

Según Castells (2000), Internet es eficaz en la creación de lazos débiles (contacto e intercambio de información) pero no es capaz de crear lazos fuertes (íntimos y primarios); por otra parte, es excelente en mantener los lazos fuertes ya existentes.

Para Lagarde (1996) la perspectiva de género implica una contribución a la creación subjetiva y social de una nueva configuración a partir de la resignificación de la historia, la sociedad, la cultura y la política desde las mujeres y con las mujeres. Así, analizar Internet desde esta perspectiva implica no sólo un compromiso educativo sino también una forma inestimable para la consecución de la equidad y la justicia social.

Lo más positivo de la globalización tiene que ver con los avances en la comunicación. Nuevas tecnologías, como las computadoras personales, Internet, los teléfonos celulares, la TV satélite, los buscadores de información como el Google, han comprimido el tiempo y el espacio, y llegado a lugares remotos. Para los grupos con poco poder político, como los movimientos sociales y en particular los movimientos de 
mujeres y feministas, la comunicación es una arma fundamental para organizarse y para desarrollar redes y coaliciones. Internet ha tenido un impacto mundial pues permite pensar localmente (consideraciones ligadas a la identidad y el interés de la comunidad o el país) y actuar globalmente (que es el espacio donde las decisiones de mayor importancia se llevan a cabo) (Castells, 2000). El sistema patriarcal está siendo debilitado por el capitalismo informativo así como por los movimientos sociales de mujeres e identidad sexual (Castells, 1997).

La globalización de la información, las nuevas posibilidades que ofrecen las TIC e Internet permitiendo la máxima difusión de información con mínimos costes, la propia estructura física de la red organizada a partir de la conexión de nodos, sin jerarquías, con igual poder desde cada nodo para emitir y recibir, son elementos especialmente favorables para poder pensar que los nuevos espacios creados son especialmente favorables para las mujeres.

El movimiento crítico a la globalización neoliberal ha reaccionado desde hace tiempo a la necesidad de producir información propia y es vanguardista en la creación de nuevas herramientas utilizando las TIC e Internet en su difusión, contribuyendo además al proceso imprescindible de la democratización de la información y la comunicación. Numerosas webs, foros, listas de distribución contribuyen en estos momentos a la distribución masiva de la información y a lograr que el mensaje llegue a la sociedad sin depender de la cobertura y del tono informativo que los grandes medios de comunicación decidan dar a determinados grupos o acciones.

En este sentido es fundamental desde los movimientos feministas incorporarse y participar en esta dinámica reivindicando además el peso que la información con perspectiva de género y la información feminista debe tener en tales medios alternativos. Internet sirve para distribuir de forma masiva y rápidamente información, para mantenernos en contacto, para debatir, para coordinar estrategias de reflexión y acción, para visibilizarnos, para darnos a conocer y ayudar a clarificar "malentendidos" históricos a menudo maliciosos sobre los movimientos feministas. 
Donna Haraway, feminista y socialista confesa, propuso un "Manifiesto para cyborgs" que nos puede ayudar a solucionar el problema de la determinación de género tras las nuevas tecnologías, plantea la posibilidad de unir dos mundos absolutamente alejados, como son el orgánico (lo natural) y el cibernético (lo artificial), y es en este sentido en el que el cyborg puede ser pensado como ya presente en todos nosotros. El cyborg, no es una meta utópica a la que debemos llegar, ya está en escena: "a finales del siglo $\mathrm{XX}$, todos somos quimeras, híbridos teorizados $\mathrm{y}$ fabricados de máquina $\mathrm{y}$ organismo; en unas palabras, somos cyborgs".

En esta última década han surgido en la Red múltiples ciberfeminismos que han ido conformando un amplio abanico de experiencias prácticas demostrando el poder de las Tecnologías de la Información y de Internet para la creación o el activismo social. El ciberfeminismo surgió en 1991, en una ciudad de Australia llamada Adelaide, cuando un grupo de mujeres -Josephine Starrs, Juliane Pierce, Francesa da Rimini y Virginia Barratt- decidió divertirse con el arte y la teoría feminista francesa. Su primera acción fue la creación de un grupo de trabajo y experimentación, VNS Matrix, en el marco del cual ensayaron su primer texto/obra de arte, Cibermanifiesto para el siglo XXI, que fue realizado como homenaje a Donna Haraway y a su concepto de cyborg.

Pasado un tiempo, las consignas ciberfeministas comenzaron a fluir por la red con su estilo irónico y contestatario. Grupos intelectuales y feministas situados en Australia, Estados Unidos y Europa se hicieron eco de la novedad surgida como una respuesta a la cultura popular del video juego, Internet y la noción de cyberpunk. El grupo se planteó como objetivo investigar y descifrar las narrativas de dominación y control que rodean a la tecnología y explorar la construcción social del espacio, la identidad y la sexualidad en el ciberespacio.

Sadie Plant, directora del Centre for Research into Cybernetic Culture de la Universidad de Warwick, e inventora, al mismo tiempo que las VNS Matrix, del término ciberfeminismo, en su libro Ceros y Unos narra una historia de la tecnología desde el punto de vista de la mujer haciendo hincapié en Ada Lovelace, la primer programadora de computadoras del mundo. Lovelace se sumergió en el mundo de las 
máquinas e inventó el sistema binario de funcionamiento de los telares automatizados, considerado precursor de la programación de computadoras. Cien años después, otra mujer, la capitán Grace Murray Hooper, se convirtió en la segunda programadora al poner en marcha el Harvard Mark. Cada vez que el feminismo intenta introducirse en nuevos territorios, los miembros de la vanguardia del movimiento se enfrentan a problemas increíbles y a obstáculos casi insuperables. El ciberfeminismo no es diferente. Relativamente pocas mujeres tienen la habilidad de ver a través de cyberhype, de entender la complejidad del sistema y lo más importante, de enseñar a otras mujeres como sobrevivir y usar activamente el sistema. Para la mayoría de las que trabajan en la tecnoesfera, el simple hecho de sobrevivir transgrediendo la norma y aprendiendo cantidades masivas de densa información tecnológica requiere de todas sus energías

Desde el grupo VNS Matrix (Venus Matrix) hasta las OBN (Old Boys Network) colectivo liderado por la alemana Cornelia Sollfrank, organizadoras en 1997 del Primer Encuentro Internacional Ciberfemista, en el marco de Documenta X, una de las ferias de arte contemporáneo más importantes del mundo que se presenta cada cinco años en Kassel (Alemania), hasta Mujeres en Red y otras redes activistas en los derechos humanos de las mujeres desde diferentes partes del mundo y en diferentes idiomas (Creatividad Feminista desde México, Penélopes en Francia, Cybersolidaires desde Canadá, etc.), reivindican el uso de la comunicación para el empoderamiento de las mujeres y la exigencia de la democratización de los medios.

Efectivamente, las tecnologías quizás estén modificando la tradicional manera de entender la vida a pesar de que la estemos utilizando con las mismas ideas con las que nos desenvolvemos en la vida real. En este sentido, esas formas con las que nos desarrollamos pueden ser interpretadas como vestigios que se disuelven cuando, situados tras la pantalla del ordenador, nos amplificamos de tal forma que el cuerpo queda atrás, olvidado. "Comunicación de consciencias puras" podríamos decir que significa el diálogo ciber-textual; o también, "perfecta unión de cuerpo y máquina al servicio de la comunicación”. Debemos recordar que estas ampliaciones y uniones eran 
entendidas por Mc Luhan como amputaciones que comenzaban a producirse tras el acceso al lenguaje (aquel yo que nos separaba de todo lo que no era yo). Quizás estemos situados en un punto limítrofe en el que el cuerpo (masculino o femenino) se encuentre a medio camino entre la desaparición y la transformación, entre la afirmación y el juego con las diversas posibilidades.

Los cambios asociados a la transición de la sociedad del bienestar a la sociedad de la información, al fenómeno social de la emigración o a la persistencia de una desigualdad jurídica, social, política y cultural entre los géneros promueven, según Bartolomé y cols. (2000), nuevas conceptualizaciones de ciudadanía que repercuten en el ámbito educativo.

Para Colás (2001) estos aspectos están determinados por la emergencia de movimientos sociales y enfoques epistemológicos como el Postmodernismo y/o el Feminismo. A lo cual hay que añadir el Movimiento de Ciencia, Tecnología y Sociedad (CTS). Por su parte, Pérez (1997) considera el feminismo como una de las perspectivas que más ha contribuido a la reflexión y análisis crítico de las relaciones entre la tecnociencia y la sociedad.

En Pekín, por primera vez se plantea en una Conferencia Mundial de la Mujer la reivindicación de la comunicación como uno de los Derechos Humanos básicos y como elemento estratégico clave para el cambio social que las mujeres exigen en la lucha por la igualdad de derechos. Las redes electrónicas ofrecen una nueva dimensión a la lucha feminista. La red provee al ciberfeminismo de un vehículo crucialmente diferente que no es de ninguna manera comparable con las anteriores olas feministas.

\section{El derecho a la educación}

Aplicado a la educación, el neoliberalismo propone una inversión mínima en la educación pública y defiende la privatización y la descentralización como modos de gestión que aseguran la mejoría educativa, tanto en acceso como en calidad. Con la privatización se vienen creando instituciones educativas con diferente reconocimiento 
Globalización y educación desde una perspectiva de género

social. Esto es especialmente visible en la educación superior, donde se han creado múltiples institutos superiores y universidades, pero la mayoría -si bien permite un acceso ensanchado y democrático- no conduce a diplomas y certificados con gran valor.

¿Qué tenemos por delante: estafa o democratización? El constante ataque a la educación pública - una entidad débil porque no está bien nutrida- contribuye a que cada vez más las familias de la clase media lleven a sus hijos a escuelas particulares. La descentralización educativa promete una mayor participación de los padres y de la comunidad; desgraciadamente, pocas veces se transfiere el poder y con frecuencia los procesos de descentralización educativa operan como estrategias para pasar el costo a los estados, regiones o municipalidades. Hablar de la educación en tiempos de globalización implica hablar de la educación en contextos de desigualdad, competencia por la excelencia y baja responsabilidad social por parte del Estado.

La declaración universal de los derechos humanos supuso un salto cualitativo importante en la aceptación de la igualdad de todos los seres humanos y su reconocimiento como sujetos de derecho independientemente de su género, raza, etnia o clase social de origen. Mucho hemos avanzado desde entonces, aunque el avance no ha sido ni lineal, ni equilibrado, ni homogéneo.

Las desigualdades económicas de la globalización se traducen en desigualdades educativas, tanto dentro de los países como entre países. Dado el mercado laboral, cada vez se necesitan más años de escolaridad para alcanzar trabajos bien remunerados que permitan la movilidad social. Como anota Reimers (2000), "a menos que existan esfuerzos deliberados por mejorar las calificaciones educativas de los niños de los pobres y por reducir la desigualdad educativa, la brecha en las oportunidades entre los que tienen privilegios educativos y económicos y aquellos que no los poseen solo podrá crecer".

Si analizamos la educación desde el marco nacional nos encontramos con países que han universalizado el derecho a la educación y organizado para ello sistemas educativos. Hay países que pueden afirmar que la totalidad de la población en edad escolar está escolarizada. En el otro extremo nos encontramos con países que aún 
reconociendo la educación como derecho no han sido capaces de organizar las estructuras necesarias para hacer efectivo este derecho.

Entre estos dos polos podemos situar al resto de los países. Esta distancia entre el reconocimiento de un derecho y la posibilidad real de ejercerlo es un factor muy importante a la hora de hablar sobre educación porque tendemos a hablar de ella como si todos compartiéramos el mismo significado y no es así. Como decía Freire el texto sólo adquiere significado en relación al contexto. Texto y contexto se interpenetran, se interseccionan, se retroalimentan. Si la educación es el texto y los territorios concretos donde se desarrolla son los contextos entonces debemos admitir que no estamos hablando de lo mismo si nos encontramos en un país con infraestructuras adecuadas para acoger a toda la población o en otro donde el acceso aun no está garantizado para todos los niños y niñas.

Por tanto, reflexionar sobre qué educación necesitamos para construir otro mundo posible pasa necesariamente por hacer explícita la distancia que hay entre el reconocimiento del derecho y la posibilidad real de ejercerlo. En el año 2000 de los más de 110 millones de niños que deberían estar escolarizados y no lo estaban, las dos terceras partes son niñas. Para ellas, la denegación de los derechos humanos es doble, pues también se les niega algo proclamado en la primera página de la Carta de las Naciones Unidas: la igualdad de derechos entre hombres y mujeres.

La globalización ha engendrado una multitud de políticas educativas. En el año 2000 se dieron dos políticas globales, la Educación para Todos (EPT) y los Objetivos de Desarrollo del Milenio de las Naciones Unidas (ODM), ambas suscritas por la mayoría de los países del mundo. Los ODMs poseen gran peso porque vienen acompañados del respaldo de los países industrializados y las agencias de desarrollo y financiamiento internacional, particularmente el G-8 y el Banco Mundial.

Dentro del marco de la EPT se habla de una educación de calidad. Desde una perspectiva feminista, la calidad educativa debería cubrir aspectos ligados al género; la UNESCO ha venido trabajando con este concepto muchos años. En principio, admite que la calidad se refiere no solo al desarrollo cognitivo de los/las estudiantes sino 
también a su desarrollo creativo y emocional. En la Conferencia de Dakar que gestó la EPT, la discusión de la calidad cubrió cuatro momentos: la calidad de los estudiantes (sanos y motivados), de los procesos (las competencias pedagógicas de los docentes), del currículo (que sea relevante), y de la calidad del sistema (buen gobierno y equidad en la distribución de recursos) (UNESCO, 2005).

En El Foro Mundial de Educación que tuvo lugar en el año 2004 y contó con la participación de más de 20.000 personas, se debatió sobre el tema de las reformas educativas que cada vez más están relacionadas con el servicio de los mercados y ha señalado como su gran prioridad una educación pública de calidad. En los informes de tal encuentro, casi no se menciona la cuestión de género, aunque uno de los temas persistentes de estos foros es que "otro mundo es posible."

\section{Conclusión}

La educación que necesitamos para construir otro mundo posible pasa por aprender y darnos cuenta de los límites de nuestro propio conocimiento, pasa por darnos cuenta de que esta forma de entender el mundo es errónea, pasa por ampliar la conciencia desde las perspectivas parciales encerradas en sí mismas a perspectivas más globales e integradoras.

La movilización de la sociedad civil, que es potenciada por la globalización, surge como imprescindible, pero exigirá mayor participación de los movimientos de mujeres y de los movimientos feministas para que la inversión educativa no solo aumente sino también se reformule para considerar aspectos de género porque como dijo Einstein "este mundo o es uno o ninguno". Queremos que sea Uno, en ello estamos todas y todos.

Hoy hablar de feminismo, es ya hablar de feminismo en red, de representaciones de las mujeres en la red, de la tecnología se está imponiendo. Hay un precio personal para entrar en la red: educación, poder invertir un cierto dinero en equipos, pero hay también un precio nacional que tiene que ver con la infraestructura de cada país. 


\section{BIBLIOGRAFÍA}

Argibay, M., Celorio, G. y Celorio, J.J. (1998): De sur a norte. Vidas paralelas de las mujeres. Bilbao: Hegoa.

BAREA, M. y BILlon, M. (2002): Globalización y nueva economía. Madrid: Encuentro Ediciones.

BerzosA, C. (2002): Los desafíos de la economía mundial en el siglo XXI. Madrid: Nivola.

ButLeR, J. (1991): Gender Trouble. London: Routledge.

- (2001): El género en disputa: El feminismo y la subversión de la identidad. México: Paidós.

Calvo, A. (2003): Integración económica y regionalismo. Madrid: Centro de Estudios Ramón Areces.

Castells, M. (1998): La era de la información. Vol.3, Fin de milenio. Madrid: Alianza.

CEPAL (2002): Globalización y desarrollo. Santiago de Chile: CEPAL.

Colas, P. (2001) "Educación e investigación en la sociedad del conocimiento: Enfoques emergentes”. En Revista de Investigación Educativa, no 19 (2), pp. 291-313.

Chomsky N. (1996): Democracia y mercados en el nuevo orden mundial. México: Ed. Contrapunto.

DuMÉNIL, G. y LÉVY, D. (2002): "Salida de crisis y nuevo capitalismo". En F. CHESNAIS et al. (eds): La globalización y sus crisis. Interpretaciones desde la economía crítica. Madrid: Viento Sur / Los libros de la catarata.

DURAN, J.J. (2001): Estrategia y economía de la empresa multinacional. Madrid: Pirámide.

EtXeZArRetA, M. (2001): “Algunos rasgos de la globalización”. En R. Fernández DURÁN, R. et al. (eds.): Globalización capitalista: luchas y resistencias. Barcelona: Virus. 
Globalización y educación desde una perspectiva de género

FERRER, A. (1996): Historia de la globalización: orígenes del orden económico mundial. Buenos Aires: Fondo de Cultura Económica.

Guillocchon, B. (2003): La globalización: ¿un futuro para todos? París: Larousse.

Held, D.; McGrew, A.; Goldblatt, D. y Perraton, J. (2002): Transformaciones globales: política, economía y cultura. México: Oxford University Press.

Holland, D. et al. (1998): Identity and agency in cultural worlds. Cambridge: Harvard University Press.

JACOBSON, J. (1994): Discriminación de género: un obstáculo para un desarrollo sostenible. Bilbao: Bakeaz.

Jordan, T. (1999): Cyberpower. The Culture and Politics of Cyberspace and the Internet. London: Routledge.

KHOR, M. (2001): La globalización desde el Sur. Estrategias para el siglo XXI. Barcelona: Icaria.

- (2002): "La agenda post Doha de la OMC". En Revista del Sur, pp. 129-130, julioagosto.

LAGARDe, M. (1996): Género y feminismo. Desarrollo humano y democracia. Madrid: Editorial Horas y Horas.

LÓPEZ, I. y AlCALDE, A.R. (1999): Relaciones de género y desarrollo. Hacia la equidad de la cooperación. Madrid: IUDC.

MAdisOn, A. (2002): La economía mundial. Una perspectiva milenaria. Madrid: OCDE / Mundi-Prensa.

Martínez Gonzalez-Tablas, A. (2000): La Economía Política de la globalización. Barcelona: Ariel.

MCDowell, L. (1999): Género, identidad y lugar. Un estudio de las geografías feministas. Madrid: Cátedra.

OIT (2004): Por una globalización justa: crear oportunidades para todos. Comisión Mundial sobre la Dimensión Social de la Globalización. Ginebra: OIT.

PABlos, J. de (1996): Tecnología y Educación. Barcelona: Cedecs. 
Palazuelos, E. (1998): La globalización financiera. La internacionalización del capital financiero a finales del XX. Madrid: Síntesis.

PAterson, C. (1996): “Críticas feministas a la dicotomía público-privado”. En C. Castell (ed.): Perspectivas feministas en teoría politica. Barcelona: Paidós.

PNUD (2001): Informe sobre desarrollo humano. 2001. Ediciones Mundi-Prensa: Nueva York.

Rebollo, M. Á. (2001): Discurso y Educación. Sevilla: Mergablum.

SAMPEDRO, J. L. (2002): El mercado y la globalización. Barcelona: Destino.

Smith, M A. y Kollock, P. (1999): Communities in Cyberspace. London: Routledge.

SORIANO, E. (coord.)(2001): Identidad cultural y ciudadanía. Madrid: La Muralla.

STiGLiTZ, J. E. (2002): El malestar en la globalización. Madrid: Taurus.

SuTCLIFFE, B. (1998, 2004): 100 imágenes de un mundo desigual. Barcelona: Intermón. Colección Libros de Encuentro.

-(2003): "El paso de fronteras en el nuevo imperialismo". En Mientras Tanto, n 89. Barcelona: Icaria.

VARElA, R. (2000): “Cultura, poder y tecnología”. En M. MEDina y T. KWIATKOwsKA (coords.): Ciencia, tecnología/naturaleza y cultura en el siglo XXI. Barcelona: Ántrhopos, pp. 133-145.

VALCÁRCEL, A. (1997): La política de las mujeres. Madrid: Cátedra. 